\title{
CONTAMINAÇÃO DE SEMENTES DE AMENDOIM, INOCULADAS POR Aspergillus seç̧ão Flavi, INFLUENCIADA PELO GENÓTIPO, PELA ÁREA DE CULTIVO E PELOS ISOLADOS
}

\author{
Contamination of peanut seeds inoculated with Aspergillus section Flavi affected by genotype, \\ cultivation area and isolate
}

\author{
Eusinia Louzada Pereira', Camila Santos Barros ${ }^{1}$, Claudia Antonia Vieira Rossetto ${ }^{2}$
}

\begin{abstract}
RESUMO
O amendoim pode ser contaminado por Aspergillus secção Flavi no solo, antes da colheita, como após a colheita, na secagem e no armazenamento. $\mathrm{O}$ crescimento desses fungos pode reduzir a germinação e causar morte do embrião. Objetivou-se, neste trabalho, avaliar a contaminação das sementes de amendoim inoculadas por A. secção Flavi, sob influência de diferentes genótipos produzidos em áreas de cultivo com e sem calagem e de distintos isolados utilizados. O delineamento experimental utilizado foi o inteiramente casualizado, em esquema fatorial: 3 (genótipos: IAC 22, BR 1 e Caiapó) x 4 (tratamentos: sem inoculação e três isolados de A. secção Flavi) x 2 (áreas de cultivo: com e sem calagem), com quatro repetições. A. secção Flavi não reduziu a porcentagem de plântulas normais sadias provenientes de sementes inoculadas dos diferentes genótipos de amendoim. As sementes de amendoim do genótipo IAC 22, produzidas em área com calagem promoveram a obtenção de menor porcentagem de plântulas anormais deterioradas.
\end{abstract}

Termos para indexação: Arachis hypogaea L., calagem, sanidade, viabilidade.

\begin{abstract}
Peanut can be contaminated by Aspergillus section Flavi in the soil before harvest and during drying and storage. The growth of this fungus can reduce germination and cause the death of the embryo. The objective of this work was to evaluate the contamination in peanut seeds inoculated with A. section Flavi influence by genotype, cultivated area and isolate. The experimental design was a 3 (genotypes: IAC 22, BR 1 and Caiapó) x 4 (treatments: without inoculation and three isolates of A. section Flavi) x 2 (cultivated areas: with or without liming) factorial, with four replicates, in a completely randomized experimental design. A. section Flavi did not reduce the percentage of healthy normal seedlings originated from the inoculated seeds of the different peanut types. Peanut seeds of genotype IAC 22 that were produced in an area with liming generated a smaller amount of abnormal seedlings.
\end{abstract}

Index terms: Arachis hypogaea L., sanitary quality, liming, viability.

(Recebido em 13 de junho de 2008 e aprovado em 24 de junho de 2009)

\section{INTRODUÇÃO}

A ocorrência de podridões de sementes e tombamentos de plântulas é frequente na cultura do amendoim (Arachis hypogaea $\mathrm{L}$ ). Nessas sementes, mais de 100 espécies de fungos têm sido identificadas, sendo muito delas responsáveis por perdas elevadas na cultura (Bellentini et al., 2005).

$\mathrm{O}$ amendoim pode ser contaminado no solo (Rossetto et al., 2003; Horn, 2005), como também após a colheita, durante o processo de secagem e no armazenamento (Usberti \& Amaral, 1999), principalmente por espécies de Aspergillus pertencentes à secção Flavi, que pode reduzir a germinação bem como causar a morte do embrião, ou seja, que estão relacionadas à deterioração das sementes (Lima \& Araujo, 1999; Brhattacharya \& Raha, 2002).
Atualmente, vêm sendo selecionados genótipos de amendoim, visando evitar ou inibir a contaminação das sementes por esses fungos (Liang et al., 2005), tendo em vista que a semente é um dos componentes que vem impulsionando o aumento do custo de produção dessa espécie (Martins, 2008). Para Mehan et al. (1981), há diferenças potenciais entre os genótipos de amendoim quanto à invasão por Aspergillus flavus, bem como entre as estirpes de A. flavus quanto à virulência entre os genótipos.

Mixon \& Rogers (1973) verificaram que a inoculação de sementes de amendoim em solução de esporos, com duas distintas estirpes de A. flavus, proporcionou diferenciação na resistência das sementes, provavelmente, devido ao fato das sementes com tegumento intacto serem mais resistentes. Também Vasedeva et al. (1989) comentaram

\footnotetext{
${ }^{1}$ Universidade Federal Rural do Rio de Janeiro/UFRRJ - Rio de Janeiro, RJ

${ }^{2}$ Universidade Federal Rural do Rio de Janeiro/UFRRJ - Departamento de Fitotecnia - Rodovia Antiga Rio São Paulo - Km 47 - Cx P. 74511 - 22890 000 - Seropedica, RJ - cavrosse@ufrrj.br
} 
que, em relação ao tegumento, deve-se considerar os fatores específicos que estão associados, tais como, uniformidade da camada cerosa, presença de taninos, compostos inibidores, acúmulo de cera na superfície, entre outros. Prado et al. (1999) ressaltaram ainda, que além do conhecimento dos mecanismos indutores de resistência, é necessário considerar as variações em função do isolado de A. flavus utilizado, seu potencial infectivo, o processo de inoculação, bem como também das condições de cultivo e colheita dos frutos a serem analisados (Usberti \& Amaral, 1999).

Com o intuito de evitar-se a contaminação tem sido recomendada a utilização de cálcio, na forma de calcário quando esse é usado como corretivo de solo para as plantas mães. Esse nutriente é importante elemento que compõe a parede celular vegetal. Sementes oriundas de solos com teores adequados de cálcio apresentam maior espessura do tegumento e da parede celular da exotesta, o que resulta em menor perda de água (Fernandez et al., 1997). No entanto, Rossetto et al. (2003) não constataram efeito significativo da calagem na redução da incidência do grupo A. flavus, em sementes de amendoim do genótipo Botutatu.

Objetivou-se, neste trabalho avaliar a contaminação de sementes de amendoim inoculadas por A. secção Flavi, sob influência de diferentes genótipos produzidos em áreas de cultivo com e sem calagem e de distintos isolados utilizados.

\section{MATERIAL E MÉTODOS}

O experimento foi conduzido na Universidade Federal Rural do Rio de Janeiro, em 2005, utilizando-se três genótipos de amendoim (IAC 22, BR 1 e Caiapó) cultivados em Planossolo, submetidos ou não à aplicação de calcário dolomítico $\left(1,2\right.$ t.ha $\left.{ }^{-1}\right)$, designados de área de cultivo $1 \mathrm{e}$ área de cultivo 2 , respectivamente. O delineamento experimental utilizado foi o inteiramente casualizado, em esquema fatorial: 3 (genótipos: IAC 22, BR 1 e Caiapó) x 4 (tratamentos: sem inoculação e três isolados de Aspergillus secção Flavi) x 2 (áreas de cultivo: 1- área com calagem e 2- área sem calagem), com quatro repetições.

Por tratamento, amostras de 304 sementes foram submetidas ou não ao procedimento de inoculação pelo método da imersão (Lima et al., 1984). Assim para a inoculação, as sementes foram imersas por cinco minutos em três distintas soluções, contendo isolado de Aspergillus secção Flavi (Takahashi et al., 2002), que corresponde ao grupo Aspergillus flavus, de acordo com a revisão apresentada por Abarca (2000), sem considerar a distinção entre A. flavus e de A. parasiticus (Klich \& Pitt, 1988), na concentração de $5 \times 10^{4}$ esporos $/ \mathrm{ml}$. Foram selecionadas estirpes de $A$ secção Flavi isoladas de sementes de amendoim do genótipo Botutatu, produzidas em $2001 \mathrm{em}$ Seropédica/RJ (Viegas, 2004) e denominadas de I, II e II.

Para a inoculação, os fungos foram mantidos em placas de Petri de $9 \mathrm{~cm}$ de diâmetro contendo meio Batata Dextrose-Agar (BDA), que foram mantidas em câmara regulada a $25^{\circ} \mathrm{C}$ e regime de 12 horas de luz, por sete dias (Berjak, 1984).

Após a inoculação e secagem sob fluxo laminar por 21 horas, as sementes foram divididas em duas amostras, sendo uma delas submetida à avaliação após a inoculação e a outra após o armazenamento durante 75 dias em câmara regulada a $18^{\circ} \mathrm{C}$ e $45 \%$ de UR do ar. Primeiramente foi realizada a determinação do grau de umidade, com quatro subamostras de 25 sementes (Brasil, 1992) e, em seguida, a instalação dos testes de sanidade, utilizando-se o método do plaqueamento direto e o de sintomas nas plântulas.

Pelo método de plaqueamento direto, oito subamostras de 13 sementes foram semeadas em meio BDA, acrescido de $\mathrm{NaCl}(6 \%)$ em placas de Petri de $9 \mathrm{~cm}$ de diâmetro e mantidas a $20^{\circ} \mathrm{C}$ e 12 horas de luz, por sete dias (Araújo et al., 2004). Após a incubação, para a caracterização dos isolados pertencentes à A. secção Flavi, empregou-se o meio diferencial de Aspergillus (ADM), com base em Bothast \& Fennell (1974). Por tratamento, os isolados foram incubados por 72 horas a $25^{\circ} \mathrm{C}$, na ausência de luz. A presença de pigmentação laranja-amarela no verso da colônia indicou reação positiva, isso é, que o isolado pertence à $A$. secção Flavi. A caracterização e a identificação das outras espécies do gênero Aspergillus foi realizada com base na taxonomia usada por Pitt \& Hocking (1997), empregando-se os meios de cultura czapeck-ágar-extrato de levedura (CYA) e Agar-extrato de malte (MEA). Além disso, também foi realizada a identificação dos fungos tais como do gênero Penicillium, Rhizopus e Fusarium, com base em Silveira (1981) e Singh et al. (1992).

Pelo método de sintomas em plântulas, quatro subamostras de 25 sementes foram semeadas a $2 \mathrm{~cm}$ de profundidade em bandejas de plástico contendo areia lavada, esterilizada e umedecida com água destilada a $60 \%$ da capacidade de retenção de água (Brasil, 1992). As caixas foram mantidas em condições de ambiente sob temperatura média de $25^{\circ} \mathrm{C}$ e UR do ar média de $64 \%$. As contagens foram efetuadas aos cinco e 10 dias após a instalação (Brasil, 1992), considerando-se a porcentagem de plântulas normais (sadias com, no mínimo, $6 \mathrm{~cm}$ de comprimento), de plântulas deterioradas (com suas estruturas essenciais deterioradas em decorrência da infecção primária, 
impedindo o desenvolvimento normal), e de sementes mortas pelo intenso crescimento de fungos.

Os dados coletados nas avaliações foram submetidos à verificação de normalidade e de homogeneidade dos erros da variância, para verificar a necessidade de transformação (Ribeiro Júnior, 2001). Posteriormente, foi feita a análise de variância individual e a avaliação da relação entre o maior e o menor quadrado médio do erro, para realizar a análise conjunta dos dados (Gomes, 1990). As comparações entre médias foram feitas pelo teste de Tukey, a 5\% de probabilidade.

\section{RESULTADOS E DISCUSSÃO}

Após a análise de variância conjunta, foi observado tanto na avaliação após a inoculação como na realizada após 75 dias de armazenamento, que não houve efeito da interação tripla entre genótipos de amendoim, áreas de cultivo da semente (com ou sem calagem) e isolados de $A$. secção Flavi, para nenhum dos parâmetros analisados (Tabelas 1 e 2).

Na Tabela 1, na avaliação realizada após a inoculação, foi constatado efeito da interação entre isolados e genótipos para porcentagem de plântulas normais, obtidas no teste de sintomas de plântulas, bem como para porcentagem de fungos total e dos pertencentes A. secção Flavi, após o método do plaqueamento direto e para teor de água das sementes. Independente da área de cultivo das sementes, houve maior porcentagem de plântulas normais sadias provenientes de sementes inoculadas com os três isolados, do que das não inoculadas, ainda que, em média, 97\% dessas sementes inoculadas apresentavam-se com fungos, sendo $93 \%$ desses fungos pertencentes A. secção Flavi (Tabela 1) e 7\% a outras espécies de Aspergillus, bem como por outros gêneros (Penicillium, Fusarium e Rhizopus) (dados não apresentados). Também, Mixon \& Rogers (1973) constataram elevada incidência de A. flavus em sementes de amendoim após inoculação em suspensão de esporos, sendo que a porcentagem de sementes contaminadas variou conforme o genótipo. No entanto, para Brhattacharya \& Raha (2002) e Bellenttini et al. (2005), as espécies de Aspergillus podem ser responsáveis pela redução da germinação, provocando tombamento de plântulas, bem como seu efeito na deterioração das sementes.Estes resultados de aumento da porcentagem de plântulas normais provenientes de sementes inoculadas, provavelmente, possam estar relacionados com a ausência de ferimentos das sementes, pois as sementes que foram utilizadas aparentemente apresentavam-se intactas. Também Horn (2005) constatou que o ferimento das sementes tem sido requerido para alta colonização fúngica por A. secção Flavi. Esses resultados podem estar relacionados ao próprio procedimento de inoculação, uma vez que a imersão das sementes em suspensão de esporos pode ter promovido o início do processo de germinação, segundo o princípio da técnica de condicionamento fisiológico (Heydecker et al., 1975).Ou seja, com o aumento do teor de água, após a absorção de água pelas sementes imersas em suspensão de esporos, de 7,75\% para valores, em média, de 10,12\% (Tabela 1), houve a inicialização do processo de germinação, com ativação enzimática e reparo metabólico, favorecendo a qualidade fisiológica das sementes. Araújo \& Rossetto (2005) também observaram efeito favorável do condicionamento fisiológico, pela técnica de hidratação controlada na germinação das sementes de amendoim.

Na Tabela 1, após a inoculação, verificou-se que, independente da área de cultivo das sementes, houve menor porcentagem de plântulas normais obtidas de sementes dos genótipos IAC 22 inoculadas com os isolados I e II e do genótipo BR1 inoculadas com o isolado III, após o método do plaqueamento direto. Esse resultado, provavelmente, está relacionado com o maior conteúdo de água dessas sementes (Tabela 1). Para Bashra et al. (1984), quanto menor o conteúdo de água das sementes, menor a capacidade de produção de fitoalexinas, que são compostos antimicrobianos produzidos pelas plantas em resposta à invasão de certos patógenos, o que resulta em atividade fúngica.

$\mathrm{Na}$ avaliação após o armazenamento, apenas houve efeito significativo de isolados para porcentagens de sementes contaminadas por fungos (total) e por $A$. secção Flavi, identificados no método do plaqueamento direto, bem como para porcentagem de sementes mortas, obtidas no teste de sintomas de plântulas. Assim, as sementes inoculadas apresentaram as maiores porcentagens de fungos, principalmente de $A$. secção Flavi e de sementes mortas do que as não inoculadas. Já para plântulas normais e para teor de água das sementes, que esteve em torno de $5,56 \%$, não houve efeito dos tratamentos (Tabela 1). Esses resultados podem estar relacionados ao equilíbrio higroscópio das sementes durante o armazenamento, que não interferiu na infecção por fungos e na porcentagem de plântulas normais sadias, ou seja na deterioração das sementes. De acordo com Bruno et al. (2000), a prevenção da contaminação por fungos durante o armazenamento ocorre quando a umidade relativa do ar é baixa e, consequentemente, o teor de água das sementes é menor, sendo ideais os valores abaixo de $7 \%$ de água para a manutenção da viabilidade da semente. 
Tabela 1 - Dados médios de porcentagem de plântulas normais e de sementes mortas avaliadas após o método de identificação de sintomas nas plântulas, bem como de fungos (total) e de A. secção Flavi identificados após o método do plaqueamento direto e de porcentagem de água, obtidos de sementes de três genótipos de amendoim. Avaliação realizada após a inoculação ou não com três isolados, designados de I, II e III e após 75 dias de armazenamento.

\begin{tabular}{|c|c|c|c|c|c|c|c|c|}
\hline \multirow[t]{3}{*}{ Genótipos } & \multicolumn{4}{|c|}{ Após a inoculação } & \multicolumn{4}{|c|}{ Após 75 dias de armazenamento } \\
\hline & \multirow{2}{*}{$\begin{array}{c}\text { Sem } \\
\text { inoculação }\end{array}$} & \multicolumn{3}{|c|}{ Isolado } & \multirow{2}{*}{$\begin{array}{c}\text { Sem } \\
\text { inoculação }\end{array}$} & \multicolumn{3}{|c|}{ Isolado } \\
\hline & & I & II & III & & I & II & III \\
\hline & \multicolumn{8}{|c|}{ Plântulas normais (\%) } \\
\hline IAC 22 & $73 \mathrm{Ba}^{*}$ & $82 \mathrm{ABa}$ & $77 \mathrm{ABb}$ & 86Aa & 81 & 74 & 75 & 76 \\
\hline BR 1 & $78 \mathrm{Ba}$ & 86Aa & 87Aa & $80 \mathrm{ABb}$ & 81 & 74 & 80 & 71 \\
\hline Caiapó & $70 \mathrm{Ba}$ & 86Aa & 84Aa & 84Aa & 83 & 79 & 91 & 80 \\
\hline Médias & 74 & 85 & 80 & 84 & $82 \mathrm{~A}$ & $76 \mathrm{~A}$ & $82 \mathrm{~A}$ & $76 \mathrm{~A}$ \\
\hline \multirow[t]{2}{*}{ C.V. $(\%)$} & 29,87 & & & & 18,09 & & & \\
\hline & \multicolumn{8}{|c|}{ Sementes mortas $(\%)$} \\
\hline IAC 22 & 10 & 8 & 14 & 6 & 4 & 10 & 12 & 10 \\
\hline BR 1 & 20 & 12 & 5 & 6 & 7 & 13 & 8 & 16 \\
\hline Caiapó & 20 & 12 & 11 & 5 & 4 & 9 & 4 & 7 \\
\hline Médias & $19 \mathrm{~A}$ & $11 \mathrm{AB}$ & $10 \mathrm{~B}$ & $6 \mathrm{~B}$ & $5 \mathrm{~B}$ & $11 \mathrm{~A}$ & $9 \mathrm{~A}$ & $11 \mathrm{~A}$ \\
\hline \multirow[t]{2}{*}{ C.V. $(\%)$} & 33,86 & & & & 39,48 & & & \\
\hline & \multicolumn{8}{|c|}{ Fungos (\%) } \\
\hline IAC 22 & $21 \mathrm{Bb}$ & 100Aa & $96 \mathrm{Aa}$ & $92 \mathrm{Aab}$ & 24 & 80 & 92 & 88 \\
\hline BR 1 & $28 \mathrm{Ba}$ & $100 \mathrm{Aa}$ & 99Aa & 98Aa & 26 & 82 & 86 & 97 \\
\hline Caiapó & $29 \mathrm{Ba}$ & 99Aa & 98Aa & $91 \mathrm{Ab}$ & 32 & 86 & 84 & 86 \\
\hline Médias & 26 & 100 & 98 & 94 & $24 B$ & $83 \mathrm{~A}$ & $87 \mathrm{~A}$ & $90 \mathrm{~A}$ \\
\hline \multirow[t]{2}{*}{ C.V. $(\%)$} & 15,77 & & & & & & & \\
\hline & \multicolumn{8}{|c|}{ A. secção Flavi $(\%)$} \\
\hline IAC 22 & $21 \mathrm{Ca}$ & 98Aa & $86 \mathrm{Bb}$ & $89 \mathrm{Bb}$ & 13 & 78 & 86 & 87 \\
\hline BR 1 & $22 \mathrm{Ca}$ & $100 \mathrm{Aa}$ & 92Bab & $86 \mathrm{Bb}$ & 16 & 78 & 90 & 83 \\
\hline Caiapó & $21 \mathrm{Ca}$ & $98 \mathrm{Aa}$ & $97 \mathrm{Ba}$ & $92 \mathrm{Aa}$ & 15 & 83 & 86 & 86 \\
\hline Médias & 21 & 99 & 92 & 89 & $15 \mathrm{~B}$ & $80 \mathrm{~A}$ & $97 \mathrm{~A}$ & $85 \mathrm{~A}$ \\
\hline \multirow[t]{2}{*}{ C.V. (\%) } & 19,10 & & & & & & & \\
\hline & \multicolumn{8}{|c|}{ Teor de água (\%) } \\
\hline IAC 22 & $7,33 \mathrm{Ba}$ & $10,93 \mathrm{Aa}$ & $11,27 \mathrm{Aa}$ & $10,47 \mathrm{Aab}$ & 5,54 & 5,54 & 5,58 & 5,61 \\
\hline BR 1 & $8,01 \mathrm{Ca}$ & $9,86 \mathrm{Bb}$ & $\begin{array}{l}10,23 \mathrm{ABa} \\
\mathrm{b}\end{array}$ & $11,48 \mathrm{Aa}$ & 5,63 & 5,74 & 5,81 & 5,85 \\
\hline Caiapó & 7,91Ca & $9,27 \mathrm{Bbc}$ & $9,14 \mathrm{ABb}$ & 9,56Aab & 5,43 & 5,24 & 5,41 & 5,37 \\
\hline Médias & 7,75 & 9,67 & 10,21 & 10,50 & $5,53 \mathrm{~A}$ & $5,50 \mathrm{~A}$ & $5,60 \mathrm{~A}$ & $5,61 \mathrm{~A}$ \\
\hline C.V. $(\%)$ & 3,77 & & & & 2,24 & & & \\
\hline
\end{tabular}

*Médias seguidas da mesma letra, maiúscula A e B na linha (isolado) e minúscula a e b na coluna (genótipos) não diferem entre si pelo teste de Tukey, a $5 \%$.

Pela tabela 2, na avaliação realizada após inoculação, foi constatado efeito da interação genótipo e área de cultivo das sementes para porcentagem de plântulas anormais deterioradas, obtidas no teste de sintomas de plântulas. Assim com a utilização dos três isolados para a inoculação, houve menor porcentagem de plântulas anormais deterioradas obtidas de sementes do genótipo IAC 22, provenientes da área de cultivo 
Tabela 2 - Dados médios de porcentagem de plântulas anormais deterioradas, obtidos de sementes de três genótipos de amendoim, provenientes de área com calagem (área de cultivo 1) e de área sem calagem (área de cultivo 2). Avaliação realizada após a inoculação ou não com três isolados, designados de I, II e III, após 75 dias de armazenamento.

\begin{tabular}{|c|c|c|c|c|c|c|c|c|}
\hline \multirow[t]{3}{*}{ Genótipos } & \multicolumn{2}{|c|}{ Sem inoculação } & \multicolumn{2}{|c|}{ Isolado I } & \multicolumn{2}{|c|}{ Isolado II } & \multicolumn{2}{|c|}{ Isolado III } \\
\hline & \multicolumn{2}{|c|}{ Área de cultivo } & \multicolumn{2}{|c|}{ Área de cultivo } & \multicolumn{2}{|c|}{ Área de cultivo } & \multicolumn{2}{|c|}{ Área de cultivo } \\
\hline & 1 & 2 & 1 & 2 & 1 & 2 & 1 & 1 \\
\hline \multicolumn{9}{|c|}{ Após a inoculação } \\
\hline IAC 22 & $6 \mathrm{Xa} *$ & $8 X a$ & $6 Y a$ & $10 X a$ & $4 \mathrm{Ya}$ & $15 \mathrm{Xa}$ & $2 \mathrm{Yb}$ & $12 \mathrm{Xa}$ \\
\hline BR 1 & $4 \mathrm{Xa}$ & $2 \mathrm{Xa}$ & $6 X a$ & $3 \mathrm{Xb}$ & $6 \mathrm{Xa}$ & $11 \mathrm{Xa}$ & $10 X a$ & $8 \mathrm{Xa}$ \\
\hline Caiapó & $2 \mathrm{Xa}$ & $2 \mathrm{Xa}$ & $3 \mathrm{Xa}$ & $3 \mathrm{Xb}$ & $7 \mathrm{Xa}$ & $9 X a$ & $6 \mathrm{Xa}$ & $8 \mathrm{Xa}$ \\
\hline Médias & 4 & 4 & 5 & 5 & 6 & 12 & 6 & 9 \\
\hline C.V. (\%) & 37,72 & & & & & & & \\
\hline \multicolumn{9}{|c|}{ Após 75 dias de armazenamento } \\
\hline IAC 22 & 0 & 2 & 7 & 8 & 3 & 5 & 6 & 13 \\
\hline BR 1 & 0 & 2 & 8 & 4 & 3 & 7 & 10 & 5 \\
\hline Caiapó & 2 & 0 & 2 & 5 & 3 & 5 & 9 & 7 \\
\hline Médias & $1 \mathrm{~B}$ & $1 \mathrm{~B}$ & $6 \mathrm{~A}$ & $6 \mathrm{~A}$ & $7 \mathrm{~A}$ & $3 \mathrm{~A}$ & $8 \mathrm{~A}$ & $8 \mathrm{~A}$ \\
\hline C.V. $(\%)$ & 36,51 & & & & & & & \\
\hline
\end{tabular}

*Médias seguidas da mesma letra, minúscula a e b na coluna (genótipos) e maiúscula X e Y na linha (área de cultivo) não diferem entre si pelo teste de Tukey, a 5\%.

designada como 1 do que das provenientes da área de cultivo 2. Pelo histórico de produção, essas sementes foram provenientes de área com calagem, após terem sido colhidas aos 120 dias após a semeadura, período considerável como favorável à obtenção de sementes com máxima qualidade fisiológica, de tal forma que essas características poderiam dificultar ou impedir a infecção por fungos do grupo A. flavus (Rossetto et al., 2004 ). Para Fernandez et al. (1997), há efeito favorável da aplicação de calcário na redução da invasão por A. flavus, provavelmente devido ao aumento de cálcio nas sementes, tornando o tegumento mais espesso, sendo que esses resultados também foram constatados por Small et al. (1989).

Pela Tabela 2, verificou-se que na avaliação realizada após o armazenamento, somente houve efeito significativo de isolados na porcentagem de plântulas anormais deterioradas, obtidas no método de sintomas em plântulas. Houve aumento da porcentagem de plântulas anormais deterioradas provenientes de sementes inoculadas do que as não inoculadas, sugerindo que, com a liberação de exsudados das sementes para o meio de hidratação, promovida após a hidratação das sementes durante a exposição à técnica de inoculação em suspensão de esporos, houve favorecimento da atividade de microrganismos. Esse resultado também pode estar relacionado ao fato de A. flavus ser agressivo, em relação ao processo de colonização e de infecção de amendoim, como também constatado por Pitt et al. (1991). Com a inoculação empregando a solução na concentração de $5 \times 10^{4}$ esporos $/ \mathrm{ml}$, os mesmos devem ter se estabelecido rapidamente, impedindo o desenvolvimento de outros fungos.

\section{CONCLUSÕES}

A. secção Flavi não reduziu a porcentagem de plântulas normais sadias, provenientes de sementes inoculadas dos diferentes genótipos de amendoim.

As sementes de amendoim do genótipo IAC 22, produzidas em área com calagem, promoveram a obtenção de menor porcentagem de plântulas anormais deterioradas.

Teores de água das sementes próximos a 5,6\%, durante o armazenamento, não contribuíram para a infecção de $A$. secção Flavi e para a diminuição da porcentagem de plântulas normais.

\section{REFERÊNCIAS BIBLIOGRÁFICAS}

ABARCA, M.L. Taxonomia e identificacion de espécies implicada em La aspergilosis nosocomial. Revista Iberoamericana de Micologia, Bilbao, v.17, p.579-584, 2000. 
ARAÚJO, A.E.S.; CASTRO, A.P.; ROSSETTO, C.A.V. Avaliação de metodologia para detecção de fungos em sementes de amendoim. Revista Brasileira de sementes, Campinas, v.26, n.2, p.45-54, 2004.

ARAÚJO, A.E.S.; ROSSETTO, C.A.V. Influência da hidratação controlada na germinação das sementes de amendoim armazenadas. Científica, Jaboticabal, v.33, n.2, p.199-207, 2005.

BASHRA, S.M.; COLE, R.J.; PIANCHOLY, S.K. A phytoalexin and aflatoxin producting peanut seed culture system. Peanut Science, Raleigh, v.21, p.130-134, 1984.

BELLENTINI, N.M.T.; ENDO, R.M.; MIGLIORANZA, E.; SANTIAGO, D.C. Patogenicidade de fungos associados às sementes e plântulas de amendoim cv. Tatu. Semina, Londrina, v.26, n.2, p.167-172, 2005.

BERJAK, P. Report of seed storage committee working group on the effects of storage fungi on seed viability. Seed Science and Technology, Zurich, v.12, n.1, p.233253, 1984.

BOTHAST, R.J.; FENNELL, D.I. A medium of rapid identification and enumeration of Aspergillus flavus and related organisms. Mycologia, Lawrence, v.66, n.3, p.365369, 1974.

BRASIL. Ministério da Agricultura e Reforma Agrária. Regras para análise de sementes. Brasília: SNDA/ DNDV/CLVA, 1992. 365p.

BRHATTACHARYA, K.; RAHA, S. Deteriorative changes of maize, groundnut and soybean seeds by fungi in storage. Mycopathologia, Dordrecht, v.155, n.2, p.135-141, 2002.

BRUNO, R.L.A.; AZERREDO, G.A.; QUEIROGA, V.P. Qualidade fisiológica e micoflora de sementes de amendoim cv. BR 1 durante o armazenamento. Revista Oleaginosas e Fibrosas, Campina Grande, v.4, n.3, p.141$152,2000$.

FERNANDEZ, E.M.; ROSOLEM, C.A.; MARINGONI, A.C.; OLIVEIRA, D.M.T. Fungus incidence on peanut grains as affected by drying method and Ca nutrition. Field Crops Research, Amesterdan, v.52, n.1, p.9-15, 1997.
GOMES, E.P. Curso de estatística experimental. 13.ed. Piracicaba: ESALQ/USP, 1990. 468p.

HEYDECKER, W.; HIGGINS, J.; TURNER, Y.T. Invigoration of seeds? Seed Science and Technology, Zurich, v.3, n.3/4, p.881-888, 1975.

HORN, B.W. Colonização of wounded peanut seeds by soil fungi: selectivity for species from Aspergillus section Flavi. Micologia, Lawrence, v.97, p.202-217, 2005.

KLICH, M.A.; PITT, J.L. A laboratory guid to common Aspergillus species and the telemorphs. North Ryde:CSIRO, 1988. 116p.

LIANG, X.G.; HOLBROOK, C.C.; LYNCH, R.E.; GUO, B.Z. â-1,3- Gluxanase activity in peanut science (Arachis hypogaea) is induced by inoculation with Aspergillus flavus and copurifies with a conglutin-like protein. Phytopathology, Saint Paul, v.95, n.5, p.506-511, 2005.

LIMA, E.F.; ARAÚJO, A.E. de. Fungos causadores de tombamento, transportados e transmitidos através da semente de amendoim. Revista Oleaginosas e Fibrosas, Campina Grande, v.3, n.2, p.71-76, 1999.

LIMA, E.F.; VIEIRA, R.M.; CARVALHO, J.M.F.C. Influência de Rhizopus spp., Aspergillus niger e Aspergillus flavus na deterioração de sementes de algodoeiro armazenadas. Fitopatologia Brasileira, Brasília, v.9, n.3, p.555-560, 1984.

MARTINS, R. Depois da boa safra em 2008, o que esperar em 2009? Análise e Indicadores do Agronegócio, São Paulo, v.3, n.11, p.1-3, 2008.

MEHAN, V.K.; McDONALD, D.; NIGAM, S.M.; LATILHA, B. Groundnut genótipos with seed resistant to invasion by Aspergillus flavus. Oléagineux, Paris, v.36, n.10, p.501-507, 1981.

MIXON, A.C.; ROGERS, K.M. Peanuts resistant to seed to invasion by Aspergillus flavus. Oleagineux, Paris, v.28, n.2, p.85-86, 1973.

PITT, J.I.; SONYA, K.; SHAREE, M.C. Systemic invasion of developing peanut plants by Aspergillus flavus.

Letters in Applied Microbiology, Oxford, v.13, n.1, p.1620, 1991. 
PITT, J.L.; HOCKING, A.D. Fungi and food spollage. London: Blackie Academic \& Professional, 1997. 175p.

PRADO, G.; OLIVEIRA, M.S.; GAZZINELLI MADEIRA, J.E.C.; GODOY, I.J.; CORREA, B.; JUNQUEIRA, R.G.;

FERREIRA, S. Resistência de quatro genótipos de amendoim à produção de aflatoxina $\mathrm{B}_{1}$ após inoculação com Aspergillus flavus Link. Ciência e Tecnologia de Alimentos, Campinas, v.19, n.1, p.84-87, 1999.

\section{RIBEIRO JÚNIOR, J.I. Análises estatísticas no SAEG.} Viçosa, MG: UFV, 2001. 301p.

ROSSETTO, C.A.V.; SILVA, O.F.; ARAUJO, A.E.S. Influencia da calagem, da época de colheita e da secagem na incidência de fungos e aflatoxinas em grãos de amendoim armazenados. Ciência Rural, Santa Maria, v.35, n.2, p.309-315, 2005.

ROSSETTO, C.A.V.; VIEGAS, E.C.; LIMA, T.M.

Contaminação fúngica do amendoim em função das doses de calcário e épocas de amostragem. Bragantia, Campinas, v.62, n.3, p.437-445, 2003.

SILVEIRA, V.D. Micologia. 5.ed. Rio de Janeiro: Âmbito Cultural, 1981. 322p.

SINGH, K.; FRISVAD, J.C.; THRAME, V.L.F.; MATHUR, S.B. An illustrated manual on identification of some seedborne aspergilli, fusara, penicilia and their mycotoxins. Denmark: Danish Government Institute of Seed Pathology for Developing Countries Ryvangs, 1992. 133p.
SMALL, H.; KVIEN, C.S.; SUMMER, M.E.; CSINOS, A.S. Solution Ca concentration and apllication date efffect on pod calcium uptake and distribution $n$ Florunner and Tifton-8 peanut. Journal of Plant Nutrition, New York, v.12, n.1, p.37-52, 1989.

TAKAHASHI, T.; CHANG, P.K.; MATUSIHIMA, K.; YU, J.; ABE, K.; BHATNAGAR, D.; CLEVELAND, T.E.; KOYAMA, Y. Nonfunctionality of Aspergillus Sojae aflR in a strain of Aspergillus parasiticus with a Disrupted afLR gene. Applied an Environmental Microbiology, Washington, v.68, n.8, p.3737-3743, 2002.

USBERTI, R.; AMARAL, H.M. Fungicide dressing timing, seed size, seed origen and fungal incidence effects on groundnut (Arachis hypogaea L.) storability. Seed Science and Technology, Zurich, v.24, n.2, p.699706, 1999.

VASEDEVA, M.J.R.; NIGAM, S.N.; MEHAN, V.K.; McDONALD, D. Aspergillus flavus resistence breeding in groundnut. In: McDONALD, D.; MEHAN, V.K. (Eds.). Patancheru: international. New York: Crop Research Institute for the Semiarid Tropics, 1989. p.345354.

VIEGAS, E.C. Emprego de óleos essenciais de plantas medicinais no controle de Aspergillus spp. em sementes de amendoim (Arachis hypogaea L.). 2004. 78p. Tese (Doutorado em Fitotecnia) - Universidade Federal Rural do Rio de Janeiro, Seropédica, 2004. 